\title{
VIDA LONGA À PENSAR A PRÁTICA
}

$\mathrm{E}$ m 2012, a revista Pensar a Prática comemora quinze anos. Ao longo desse período, mais de 300 artigos foram publicados em suas páginas. Seu primeiro número foi lançado em 1998 e em seu editorial assinado por Antônio Celso Ferreira Fonseca, diretor da Faculdade de Educação Física da UFG à época, a revista entendia-se como "científico-pedagógica", movida por um forte compromisso com a reflexão sobre a prática educativa - escolar, sobretudo. A prática pedagógica e social, dizia Fonseca, devia mesmo funcionar como o "marco referencial" do novo periódico, o que de certo modo, justifica o próprio nome da revista, cujo significado fala por si: pensar a prática.

No segundo volume da revista, em 1999, o professor Nivaldo Antonio Nogueira David, como diretor da Faculdade à época, assinou o editorial daquele ano, além de ter se responsabilizado pelas entrevistas realizadas com educadores de renome, que seriam publicadas até o quarto volume, em 2001. Grande parte dos textos publicados nesse período refletia a preocupação central com temas vinculados à "Educação Física escolar" e à "formação de professores".

Inicialmente, a Pensar a Prática vinculava-se com cinco seções: "entrevista", "artigos originais", "relato de experiência", "ponto de vista" e "seção de resumos", acrescidas, a partir do segundo volume, em 1999, de uma seção de "resenhas". Embora nenhuma mudança da política de seção tenha sido formalmente anunciada em seus editoriais, essa configuração parece ter prevalecido apenas até 1999. Gradativamente foram se extinguindo as seções de entrevista e de relatos de experiências, alterando-se as demais, provavelmente de acordo com as possibilidades oferecidas pela demanda de então, cuja amostra figura nas páginas da revista.

No terceiro volume, publicado em 2000, Anegleyce Teodoro Rodrigues, atualmente diretora da Faculdade, e Fernando Mascarenhas, agora professor na Universidade de Brasília, assumiram a editoria da revista, imprimindo-lhe algumas mudanças. Uma delas foi a ampliação do escopo editorial, doravante, abrangendo também "atividade física", "saúde" e "lazer". A mudança, amiúde, refletia os rumos e tendências da própria Faculdade. No quinto volume, em 2002, no momento em que a Faculdade inaugurava dois novos cursos de especialização ("Atividade Física e Saúde" e "Lazer e Educação", que se 
somaram ao curso em "Educação Física Escolar"), esta maior abrangência foi reiterada, ao mesmo tempo em que a publicação de fascículos dedicados a temas específicos foi adotada como política editorial. O primeiro tema foi dedicado à "Educação Física e infância".

Edições temáticas foram organizadas até 2008, quando a revista abandonou o formato em favor do recebimento de um fluxo livre de artigos. Nesse período, "dança e educação", "futebol" e "jogos olímpicos" estiveram entre alguns dos assuntos contemplados pela revista.

Até 2003 sua periodicidade era anual, embora uma periodicidade semestral estivesse nos planos da sua política editorial desde o ano 2000, quando a mudança chegou a ser anunciada pelos editores. A mudança, contudo, efetivou-se apenas quatro anos depois, em 2004, no momento em que Anegleyce Teodoro Rodrigues assumia a vice-direção da Faculdade, despedindo-se da editoria da revista, substituída, então, pelo professor Ari Lazzarotti Filho. Na sequencia, a professora Valéria Maria Chaves de Figueiredo juntar-se-ia a editoria da revista, trabalhando no periódico até os dias de hoje.

Uma série de transformações inauguradas a partir daí seriam responsáveis pelas atuais características da Pensar a Prática. Em 2004, a revista disputaria e receberia apoio financeiro do Programa de Apoio às Publicações Periódicas da Pró-Reitoria de Pesquisa e Pós-Graduação da UFG, destinada, precisamente, a estimular o desenvolvimento dos periódicos da instituição. Nesse sentido, o editorial do segundo número de 2004 já destacava "preocupações com critérios de cientificidade e qualidade construídos a partir dos indexadores reconhecidos pelas agências de fomento". Em 2005, o editorial do segundo número anunciava que aquele fascículo fora lançado em Porto Alegre, durante o XIV Congresso Brasileiro de Ciências do Esporte e I Congresso Internacional de Ciências do Esporte, numa clara tentativa de aumentar o alcance e mesmo a representatividade da revista junto à comunidade científica nacional e também internacional. Em 2006, alterou-se o design gráfico da capa, tornando-a mais sóbria. Os desenhos feitos por crianças estudantes de escolas municipais de Goiânia foram substituídos por um padrão monocromático, até que em 2008, a revista ganha a logo e o design adotados até a atualidade. Em 2007, além do formato impresso, a revista passou também a ser publicada eletronicamente, o que fez da Pensar a Prática a primeira revista brasileira da Educação Física a utilizar o Sistema Eletrônico de Editoração de Revistas (SEER), hoje plenamente disseminado entre vários periódicos. Além dis- 
so, a revista recebeu nesse ano financiamento do Ministério do Esporte, o que se repetiria por três anos mais, o que possibilitou a consolidação da nova política editorial. Em 2008, novas mudanças: primeiro, ampliou-se novamente o conselho editorial da revista; segundo, assumiu-se uma periodicidade quadrimestral; terceiro, criou-se nova função editorial, o chamado "editor de seção", cuja principal tarefa era e é ainda auxiliar os editores na avaliação de manuscritos submetidos à revista; quarto, a professora Ana Márcia Silva, recém transferida de Florianópolis para Goiânia, juntou-se à equipe de editores. Entre 2009 e 2010, na esteira da expansão pela qual passava toda a UFG, professores recém-contratados foram se incorporando à equipe editorial. Foi esse o caso dos professores Cleber Dias, Eduardo Henrique Rosa Santos, Tadeu João Ribeiro Baptista e Paulo Roberto Pereira Santiago.

Nos anos iniciais, a maioria dos autores que figuravam nas páginas da Pensar a Prática atuava mesmo em Goiás. Nesse sentido, pode-se dizer que parte da história recente da Educação Física da região, sobretudo as idéias que orientavam práticas pedagógicas e científicas desse campo acadêmico-científico no Estado passou pelas páginas da revista. Com o passar do tempo, porém, a revista transcendeu essa sua conformação regional, integrando-se, definitivamente, na dinâmica nacional e internacional de produção do conhecimento em Educação Física. Indício desse processo é o aumento vertiginoso do número de trabalhos submetidos à avaliação da revista, o qual atesta a relevância do periódico para veiculação do conhecimento científico dessa área. Em 2007, para o segundo número do volume 10, 33 artigos foram recebidos para avaliação, totalizando, aproximadamente, 60 artigos submetidos ao longo de todo aquele ano. No fim de 2010, este número atingiria a impressionante marca de 220 trabalhos, representando, portanto, aumento de quase $400 \%$ num período de três anos! No início de dezembro de 2011, o sistema de gerenciamento eletrônico da revista registrava 248 artigos: um aumento de $10 \%$ em relação ao ano anterior. Para 2012, nossa expectativa é de que 260 artigos, aproximadamente, sejam submetidos à avaliação da revista. Os dados parciais até o momento em que redigimos este editorial, em meados de março, confirmam e até extrapolam essas expectativas, pois o sistema de gerenciamento eletrônico da revista já registra a submissão de mais de 60 artigos, indicando um fluxo de submissão crescente.

Todos esses elementos exigem mudanças para o ano de 2012. A primeira delas, com o propósito de atender a crescente demanda de 
pesquisadores do Brasil e do exterior, diz respeito a uma nova periodicidade, que passará a ser trimestral. A medida faz parte das ações comemorativas pelo décimo quinto aniversário da revista, bem como o lançamento de uma logo especial a ser veiculada apenas nesse ano. Desse modo, excetuando-se eventuais números especiais, serão ao menos quatro números por ano com os quais se ultrapassará o somatório de 60 artigos a cada ano, número superior ao total de artigos publicados ao longo dos seis primeiros anos da revista. É mais um indicativo da intensidade com que a Pensar a Prática participa atualmente das dinâmicas científicas do campo da Educação Física, o qual também passa por um período de forte expansão.

Ainda como parte das comemorações pelo aniversário da revista, o primeiro número desse décimo quinto volume consiste num dossiê temático especial, dedicado, especificamente, às "Práticas Corporais e Culturas Tradicionais". Embora a política editorial da revista não prescreva mais números temáticos, ações pela comemoração desse aniversário animaram e justificaram a iniciativa, assim como o reconhecimento da função social que um periódico pode desempenhar, pautando temas candentes na dinâmica social e acadêmica.

Ações sociais e políticas em várias áreas têm sofrido mudanças cada vez maiores nas concepções que as orientam. Nomeadamente, iniciativas endereçadas a mulheres, negros, deficientes, grupos étnicos minoritários e outras "minorias sociais", em suma, reorganizam parte dos fundamentos epistêmicos da ação política, mas também da investigação acadêmica. "Política de identidade", "ações afirmativas", "discriminação positiva" são alguns dos termos que emergem desta agenda contemporânea. Como não poderia deixar de ser, a Educação Física, de modo geral, é também convocada a dar respostas a esses desafios. Nesse sentido, este fascículo da Pensar a Prática apresenta trabalhos de pesquisadores de diferentes partes do mundo sobre a relação entre práticas corporais e culturas tradicionais. A questão fundamental que os orienta, em outras palavras, é a de refletir sobre as maneiras através das quais práticas corporais do universo da Educação Física, como os esportes e o lazer, têm se relacionado com as particularidades de inúmeras culturas tradicionais. Para uma primeira contribuição à temática, julgamos que um panorama internacional seria mais que pertinente, pois, por paradoxal que pareça, o movimento de revitalização de culturas tradicionais articula-se profundamente com processos recentes de globalização: problemas locais cuja solução ou compreensão 
requer perspectivas globais. Apenas neste fascículo, pesquisadores do Canadá, Nova Zelândia, Austrália, Inglaterra, Portugal, Espanha e Colômbia, além de brasileiros de diferentes regiões do país, têm seus trabalhos publicados nas páginas da revista.

Outra mudança importante é a despedida do professor Ari Lazzarotti Filho da equipe editorial da revista. Depois de quase oito anos à frente do periódico como editor, Lazzarotti afasta-se da função, embora continue sua intensa colaboração por meio sua presença no Conselho Editorial. Não podemos deixar de registrar nossa gratidão ao modo sempre fraterno, rigoroso e extremamente colaborativo que marca a atuação desse professor, tanto no trabalho editorial da Pensar a Prática, quanto em outras ações da nossa Faculdade. É com certeza um grande privilégio compartilhar do mesmo ambiente de trabalho, pelo que tecemos loas ao nosso companheiro, como a todos aqueles que contribuíram com a revista ao longo desses 15 anos, nesta importante função acadêmica.

Com este breve panorama, esperamos registrar a energia desta jovem revista e reiterar: Vida Longa à Pensar a Prática!

Cleber Dias

Ana Márcia Silva

Editores 